\title{
ENKELE BESCHOUWINGEN OMTRENT EN ENKELE INDRUKKEN VAN EEN STUDIEREIS NAAR DE VERENIGDE STATEN VAN AMERIKA
}

\author{
door G. Diephuis
}

Onder auspiciën van de Economic Cooperation Administration heeft een Nederlandse textielteam kortgeleden een studiereis naar de Verenigde Staten van Amerika gemaakt. Het doel van deze reis was de oorzaak van de hogere arbeidsproductiviteit in de Amerikaanse katoen- en rayonindustrie te bestuderen, alsmede de gevolgen hiervan op het materiële welvaartspeil en het sociale leven van de betrokkenen. Van de onderwerpen, t.a. waarvan het team in het raam van de genoemde algemene doelstelling, in het bijzonder geïntersseerd was, worden genoemd:

Administration and organization,

Cost-accounting.

Het team was gevormd uit twee groepen n.l. een spinnersgroep en een weversgroep. Het was samengesteld uit vertegenwoordigers van werkgevers- en van werknemerszijde, aangevuld met enkele specialisten.

In de U.S.A. werd het team in de gelegenheid gesteld een aantal fabrieken (plants), researchinstituten en verkooporganisaties te bezoeken. Voorts werden een aantal voordrachten van vakverenigingsleiders, do centen van een textiel-opleidingsinstituut en lezingen vanwege de American Council on Education en het U.S. Department of Labor voor het team georganiseerd. Deze voordrachten enz. waren in het programma opgenomen om het team ,the background of the industry" en ,the American way of life" te leren kennen.

Het team heeft van te voren geen invloed kunnen uitoefenen op het programma. Het kant- en -klaar "Program and Itinerary" werd eerst bij aankomst in New-York overhandigd en was dus één van de eerste verrassingen voor het team in de Nieuwe Wereld. De volgende areas werden bezocht:

New-York, N.Y.,

Manchester, New Hampshire,

Boston, Massachusetts,

Hartford, Connecticut.

Philadelphia, Pennsylvania,

Columbia, South Carolina en

Washington, D.C.

Van de meeste van deze centra uit werden trips naar fabrieken in verschillende plaatsen gemaakt.

Uit deze opsomming blijkt, dat zowel de "oudere" industrie in het Noord-Oosten (New England), als de .,jongere" in het Zuid-Oosten van de U.S.A. werd bezocht. Dit was van belang, omdat de in het N.O. gevestigde (gevariëerde) textielindustrie meer overeenkomst vertoont met de Nederlandse dan de in het Z.O. gevestigde, welke zeer gespecialiseerd is.

Met een betrekkelijk groot aantal gegevens omtrent de situatie in de eigen Nederlandse bedrijfstak gewapend, ging het team op reis. Deze gegevens waren van te voren door een uitgebreid onderzoek in de be- 
drijfstak verzameld. Hierdoor was men veelal in staat naast de in Amerika verzamelde gegevens direct de overeenkomstige Nederlandse productiviteitscijfers te leggen. Op deze wijze kon steeds snel worden vastgesteld of een dieper onderzoek in een bedrijf al of niet interessant zou kunnen zijn. In aanmerking moet n.l. worden genomen, dat voor elk bedrijfsbezoek maximaal ca. vier uur ter beschikking stonden en verder nog ca. een uur voor ",discussion and question-and-answer period". Enige zelfbeperking in het onderzoek resp. in het stellen van vragen was dus zeer wenselijk.

$\mathrm{Om}$ in genoemd tijdsbestek zo nuttig mogelijk werkzaam te zijn, waren de verschillende taken over verschillende (groepen van) teamleden verdeeld. Zodra een fabriek werd binnen gestapt wist iedereen welke onderdelen van het onderzoek door hem verricht moesten worden.

Van te voren was een "generale repetitie" in Nederland gehouden. In teamverband waren n.l. enkele Nederlandse textielbedrijven bezocht. Deze .,repetitie" is zeer nuttig geweest.

Men was er zich van te voren van bewust, dat de arbeidsproductiviteit in de textielindustrie van de U.S.A. in het algemeen hoger ligt dan gemiddeld in de Nederlandse bedrijven. Een en ander was gebleken uit rapporten van de Anglo-American Council on Productivity, de dissertatie van Dr. H. D. Nijhuis ${ }^{1}$ ) en uit ander gepubliceerd (statistisch) materiaal. Waardevolle gegevens uit de bedoelde rapporten hebben dan ook mede de richting bepaald, waarin het team zijn onderzoekingen heeft verricht.

Een goede voorbereiding van de reis, in het bijzonder t.a.v. het opstellen van de enquête-formulieren, het verzamelen van gegevens omtrent de eigen bedrijfstak in Nederland en het verdelen van de taken in het team. lijkt mij een conditio sine qua non voor het welslagen van een dergelijke studiereis. En last but not least het bestaan van een goede teamgeest welke in dit team wel uitstekend was. Het leek mij wenselijk deze ervaringen te vermelden in verband met eventueel nog volgende studiereizen van teams uit andere bedrijfstakken.

Ten aanzien van het bestuderen resp. het vergelijken van de arbeidsproductiviteit in dezelfde bedrijfstak van verschillende landen kan men globaal gezegd van drie methoden gebruik maken en wel:

1e. de meest globale methode, welke is gebaseerd op de vergelijking van de totale productie en de totale personeelsbezetting in de desbetreffende bedrijfstak;

2e. de methode, welke gebaseerd is op een vergelijken van de gegevens van enkele hiertoe uitgezochte bedrijven, welke ongeveer dezelfde producten maken en zo mogelijk onder gelijksoortige omstandigheden werken;

3e. de methode, welke is gebaseerd op een vergelijken van de waarde van de productie per man-uur in de desbetreffende bedrijfstak van de verschillende landen, omgerekend in dezelfde monetaire eenheid (bijv. op basis van Paniers de provision).

Het team moest (een surogaat van) de sub 2 aangegeven methode volgen.

Wat is nu arbeidsproductiviteit? De definitie, welke gegeven werd op het Department of Labor in Washington D.C., luidde: „Productivity is

${ }^{1}$ ) Dr. H. D. Nijhuis. De structuele ontwikkeling van de Nederlandse Katoen-, Rayonen Linnenindustrie.

$\mathrm{m}$ a b blz. 272 
the output per manhour". Deze definitie komt overeen met de hier in Nederland gebruikelijke, i.c. de productie per man per uur ${ }^{2}$ ). Voor het meten van (de veranderingen in) de productiviteit, alleen in technische betekenis, is deze definitie ook wel de meest aanbevelenswaardige (methode sub 2). Voor andere doeleinden, bijv. het meten van resp. het vergelijken van het reële inkomen in verschillende landen, wordt als begrip productiviteit wel gebruikt de productie per man per jaar ${ }^{3}$ ). Het verschil in betekenis van deze definities laat ik, evenals de invloed van het gebruik van de een of de andere bij het treffen van vergelijkingen, hier buiten beschouwing. In het vervolg zal het begrip productiviteit alleen in eerstgenoemde betekenis worden gebruikt.

De eenzijdigheid van het begrip productiviteit komt in de definitie naar voren. De productie wordt n.l. zeer eenzijdig alleen met de arbeid (manuur) in relatie gebracht. Een productiviteitsvergelijking zonder meer zegt dan ook heel weinig. In de eerste plaats moet men er op bedacht zijn. dat geen vergelijking wordt getroffen tussen het productiviteitscijfer van kwalitatief niet-gelijke producten. Een vergelijken van deze cijfers is eigenlijk alleen maar verantwoord, wanneer de invloed van de afwijking in de kwaliteit op deze cijfers betrekkelijk nauwkeurig kan worden geelimineerd.

In de tweede plaats moet bij een vergelijken in aanmerking worden genomen het verschil in productie-omstandigheden, dat wil zeggen de omstandigheden, waaronder de desbetreffende productiviteitscijfers zijn behaald, omdat zij mede de productiviteit beinvloeden, zonder dat zij op rekening van de manuale arbeid kunnen worden geschreven. Als voorbeeld noem ik enkele:

kwaliteit van de verwerkte grondstoffen,

mate van mechanisatie,

afzetverhoudingen enz.

De grote moeilijkheid nu is, dat de invloed van het grote aantal verschillen in deze omstandigheden practisch gesproken niet onder één noemer is te brengen, i.c. niet te meten is en als zodanig niet als een correctie op het cijfer van de arbeidsproductiviteit kan worden aangebracht. Het grote gevaar is, dat bij het treffen van vergelijkingen deze verschillen worden geïgnoreerd, waardoor in wezen een misbruik wordt gemaakt van de productiviteitscijfers.

Prof. v. d. Schroeff heeft in zijn schets, opgenomen in het Octobernummer 1951 van dit maandblad, er reeds op gewezen, dat het begrip productiviteit zeker niet verward moet worden met het begrip efficientie. Zowel de mate van productiviteit als de mate van efficientie komen uiteindelijk tot uitdrukking in de hoogte van de kostprijs. Het was daarom jammer, dat bij de verschillende fabrieken omtrent de hoogte en de samenstelling van de kostprijzen niet voldoende gegevens konden worden verkregen om een oordeel te vormen. Deze fabrieken waren n.l. in de meeste gevallen alleen maar "technische" units. De in de U.S.A. veel voorkomende structuur t.a.v. de grote ondernemingen is deze, dat het bedrijf is gesplitst in meerdere plaatselijke units (plants). Het hoofdkantoor met de verschillende stafafdelingen zetelt veelal in een der centra (New-York,

$\left.{ }^{2}\right)$ Prae-advies van Mr. J. A. Berger, uitgebracht op de vergadering van de Ver. voor de Staatshuishoudkunde dd. 15 December 1951.

Prae-advies van Ir. A. J. Ingen Housz voor de „Efficiency-dagen” 1951.

3) Zie bijv. L. Rostas, Comparative Productivity in British and American Industry.

$\mathrm{m} \mathrm{a} \mathrm{b}$ blz. 273 
Boston, Philadelphia enz.). Het gevolg hiervan was, dat bij het voorgeschreven reisplan in vele gevallen geen contact kon worden opgenomen met bedoelde afdelingen, zodat in deze gevallen t.a.v. problemen betreffende ,administration and organization, cost-accounting etc." geen uitwisseling van ervaring resp. het inwinnen van informaties mogelijk was. Waren deze kostprijsgegevens wel verkregen, dan had het team, zo gewenst, direct ter plaatse de verhoudingen kunnen bestuderen, waaronder een eventueel lagere kostprijs werd bereikt. Er mag dan nog niet gesteld worden, dat wanneer deze omstandigheden nu maar getransponeerd worden op de Nederlandse bedrijven, de kostprijs hier ook zal dalen. Dit hangt o.m. weer af van de onderlinge verhouding van prijsniveaux van de verschillende kostprijsfactoren in beide landen.

De factoren nu resp. de omstandigheden, welke meewerken aan een grotere arbeidsproductiviteit in de U.S.A., deel ik enigszins globaal in twee groepen in, t.w.:

I. Mentale resp. psychologische factoren,

II. Economische factoren.

Ik stel hierbij in rangorde de eerstgenoemde voorop, omdat deze naar mijn mening voor Nederland wel de meest belangrijke is. Van beide groepen noem ik de volgende:

I. Mentale resp. psychologische factoren.

a. Bij werknemers.

De Amerikaanse werknemer is er in het algemeen van overtuigd, dat een hoog welvaartspeil alleen te bereiken en te handhaven is bij een grote arbeidsproductiviteit. Deze gedachte leeft zeker bij de vakverenigingsleiders. Er bestaat dan ook geen tegenwerking van de zijde der vakverenigingen bij een verlagen van de prestatielonen, wanneer de omstandigheden (bijv. arbeidsbesparende hulpmiddelen) hiertoe aanleiding geven.

b. Bij werkgevers.

Hoge lonen verhogen de arbeidsvreugde en als zodanig de arbeidsproductiviteit. Hierbij is nog te voegen het voordeel, dat hoge lonen het consumptieniveau van de werknemers gunstig beinvloeden en als zodanig de afzetmogelijkheden van de industrie (invloed van Henry Ford?).

c. Zowel bij werknemers als bij werkgevers.

Het handhaven van goede "human relations" wordt wederzijds betracht.

Bij beide groepen leeft de idee van de „,free-enterprise", waardoor men "wakker" blijft.

d. T.a.v. de verhouding tussen uitvoering en leiding.

De gezagsverhoudingen in de bedrijven zijn minder politioneel dan in Nederland. Er is minder afstand tussen leidende en uitvoerende functies. De verhoudingen zijn meer sportief, meer gericht op het kweken van een team-spirit. Psychologisch liggen de verhoudingen in de U.S.A. mijns inziens beter. En dit ondanks het feit, dat de sociale omstandigheden als geheel op een lager niveau liggen. Ontslag is steeds mogelijk en gebeurt dan ook herhaaldelijk. Men neemt dit sportiever. In de wedstrijd heeft men een bepaalde taak niet gehaald en men probeert het elders dan nog 
maar weer eens. Opmerkelijk is ook het feit, dat de beloning van mannen en vrouwen voor hetzelfde werk gelijk is: equal work, equal pay.

Of deze team-spirit gegroeid is van de "gevoelsfeer" uit of gekweekt is vanuit de "verstandelijke" sfeer vermag ik niet te beoordelen. Ik neig naar de laatste veronderstelling.

In de U.S.A. past men een ruimere delegatie van verantwoordelijkheden toe, waardoor meer mogelijkheden ontstaan tot het ontplooien van initiatieven (arbeidsvreugde!). Een en ander wordt nog gestimuleerd door het treffen van bijzondere maatregelen (ideeënbus).

De baas in de U.S.A. is anders dan de Nederlandse. In Nederland is hij in 't algemeen gesproken een prima vakman, die zijn gereedschappen door en door kent. In Amerika is hij meer de leider van mensen, die de verschillende productiekrachten in zijn afdeling moet coördineren en de samenwerking, het samenspel tot stand moet brengen (team-spirit!). Dat de invloed van het onderwijs hierbij een belangrijke rol speelt lijkt we] waarschijnlijk.

\section{e. T.a.v. de verhouding stafafdelingen en productieafdelingen.}

Deze ligt naar mijn gevoel in de U.S.A. goed. Ik heb niet die animositeit tussen deze twee groepen gemerkt, welke in Nederlandse bedrijven nog dikwijls voorkomt.

\section{Economische factoren.}

a. De grotere nationale markt in de U.S.A. opent de mogelijkheid van grotere fabricage-runs. (Volgens een mededeling op het U.S. Department of Labor te Washington D.C. zou ca. $90 \%$ van de nationale productie in het binnenland worden verbruikt!) Het typische is, dat, ondanks de grote uitgestrektheid en vele bevolkingsgroepen in de U.S.A., toch van een betrekkelijk eenvormige nationale markt kan worden gesproken. Er is een betrekkelijk grote standaardisatie van de smaak ${ }^{4}$ ).

Met zit dientengevolge niet met de problemen van vele markten met elk haar typische eisen van uitvoering (opmaak, kwaliteit, breedten enz. enz.).

b. De grote nationale markt opent verder grotere mogelijkheden voor specialisatie. In Nederland is specialisatie niet altijd mogelijk, omdat de toch al kleine markt dan nog verder ingekrompen wordt.

c. Splitsen van het totale bedrijf van een onderneming in meerdere kleine plaatselijke units. Hierdoor krijgt men overzichtelijker eenheden, met een decentralisatie van de leiding. Aan de plaatselijke directie worden grote bevoegdheden gedelegeerd. Qua bedrijfsleiding kan men voor deze kleine units volstaan met leiders van lager niveau, waarvan er meer aanwezig zijn, terwijl de topleiding van de onderneming haar handen vrij houdt voor arbeid op hoger nievau, i.c. het aangeven van de algemene bedrijfspolitiek, w.o. het ontwikkelen van bepaalde verkoopmarkten, het aandacht schenken aan de resultaten van de research enz. Deze kleinere fabrieksunits in dezelfde onderneming verschaffen ook de mogelijkheid om per unit te specialiseren.

Waar elke unit op zich zelf overzichtelijker is, kan de administratie eenvoudiger zijn. Ook de contrôle kan eenvoudiger zijn resp. intensiever worden uitgevoerd.

$\left.{ }^{4}\right)$ Zie bijv. Prof. Dr. P. J. Bouman, Volk in Beweging, pag. 27: Standaardizering van de levensstijl. 
d. De grote natuurlijke rijkdom van de U.S.A. en de relatief geringe bevolkingsdichtheid maken het mogelijk, dat per werker een grote kapitaalsinvestering kan plaats vinden. Een en ander uit zich in de verhouding van het kostenniveau van mechanische arbeid en manuale arbeid. Deze verhouding ligt in de U.S.A. tegengesteld aan die in Nederland. Het gevolg is dan ook, dat men in de U.S.A. in de eerste plaats de manuale arbeid benut, zo nodig door het ter beschikking stellen van meer mechanische hulpmiddelen (automatisch transport!) en niet in de eerste plaats de machine. De machinerendementen liggen dan ook in vele gevallen in de textielbedrijven in de U.S.A. niet beter dan bij ons.

e. Als gevolg van bedoelde grote rijkdom is men eerder geneigd nieuwere "snufjes" te aanvaarden. Men is eerder geneigd tot het vervangen resp. moderniseren van het machinepark, resp. het overnemen van nieuwe ideeën. Men moet hierbij wel in aanmerking nemen, dat bij het werken in drie ploegen, zoals in vele textielbedrijven in de U.S.A. gewoonte is, er een grotere mogelijkheid tot amortiseren van de apparatuur aanwezig is dan in Nederland, waar als gemiddelde zeker nog niet in twee ploegen wordt gewerkt. Men durft door de grotere economische kracht van het land als ondernemer (onbewust) groter risico's te aanvaarden. Mede hierdoor is de leiding zeer dynamisch geworden. (Een en ander uit zich in alle bevolkingslagen. Als er iets nieuws op de markt komt, koopt men het, omdat men het ",nieuwe" wil hebben. In ons land kijkt men eerst de kat uit de boom. Ook is typerend, dat het blijkbaar geen "schande" is om eens failliet te gaan; men krijgt wel weer nieuwe kansen! De risico's aanvaardt men ook in de consequenties.)

f. Een grote standaardisatie ten aanzien van alle productiefactoren. resp. omstandigheden, zoals bijv. van de grondstoffen, de arbeid, de apparatuur, temperatuur, vochtigheid enz. Hoe verder men hiermede gaat, hoe beter men de productie in de hand kan houden, hoe beter planning, voorcalculatie enz. tot hun recht komen. Opmerkelijk in de textielbedrijven waren de vele maatregelen tot het beheersen van de kwaliteit. De bedrijfsorganisatie zowel technisch als administratief, was naar mijn mening dan ook in vele gevallen beter dan wat gemiddeld in de Nederlandse textielbedrijven wordt aangetroffen. Men onderkent m.i. de belangrijke diensten, welke een goede administratie en kostprijsberekening zowel voor de planning als voor de efficientie-contrōle kunnen bewijzen.

De algemene indruk t.a.v. de administratie en kostprijsberekening, welke ik heb gevormd op basis van slechts enkele waarnemingen, is, dat deze niet beter zijn dan die, welke in Nederland bij vooruitstrevende bedrijven worden toegepast. Gebruik van methoden, welke bij ons in Nederland niet bekend zijn, heb ik niet gezien. Men ",werkt" evenwel meer met de gegevens. Een eenmaal vastgelegd gegeven beschouwt men niet als afgedaan, maar als een uitgangspunt voor het samenstellen van veel statistisch materiaal. Als materiaal voor de vergelijking met de (door de overheid en andere instanties) gepubliceerde statistieken (waartoe het eigen materiaal grif ter beschikking wordt gesteld!), dus om de eigen relatieve positie te leren kennen en ter richting van de eigen bedrijfsactiviteit (stimuleren van verkoopactiviteit, bedrijfscontrôle enz.). Het komt mij voor, dat juist t.a.v. het statistisch materiaal de U.S.A. vóór is, in het bijzonder waar het geldt het vlug ter beschikking stellen. In Nederland wordt nog te dikwijls de grote waarde van goede statistieken onderschat. 
Het meer "werken" met de administratieve gegevens beperkte zich in de regel tot het louter constateren van de feiten, zonder de oorzaken van het optreden ervan na te gaan (bijv. ten aanzien van de afwijking tussen budget en werkelijkheid). In Nederland probeert men in het algemeen te komen tot de analyse. tot de oorzaken, welke tot het optreden van bepaalde feiten (bijv. afwijkingen van het budget) aanleiding hebben gegeven. Wanneer een afwijking in ongunstige zin optreedt, geeft men in Amerika nog wel eens een globale analyse. Het gevaar van deze werkwijze zal de lezer duidelijk zijn; bij een voordelig verschil worden de "negatieve" factoren, welke ook aan dit verschil hebben meegewerkt, niet gesignaleerd.

Misschien is deze werkwijze gegroeid, doordat men een zeer gedetailleerd budget, een zeer gedetailleerde voorcalculatie maakt. Bij de ver doorgevoerde standaardisatie is dit te doen. En bij een gedetailleerde voorcalculatie met een standaardisatie van de productieomstandigheden, waardoor men dus tracht alle omstandigheden zoveel mogelijk te beheersen om een uitkomst ,zonder afwijkingen" te krijgen, kan met een globale nacalculatie voor de bedrijfscontrôle worden volstaan. Dit wordt in het algemeen nog geaccentueerd door de toegepaste specialisatie, waardoor het bedrijf op zichzelf al overzichtelijker is.

Deze specialisatie, welke in vele van de bezochte fabrieken werd doorgevoerd, maakt het uiteraard mogelijk, dat de bedrijfsadministratie eenvoudiger kan worden gehouden dan in een bedrijf met een gevarieerde productie.

De bedrijfsadministrateurs (controller, cost-accountant e.d.) verschaffen veel voorlichting aan de leiding buiten de routinerapporten om. Ze zijn meer administrateur en minder boekhouder, ze zijn zeer dynamisch. Men probeert aan de hand van verwerkt materiaal (statistiek!) tendenzen op te sporen, waardoor men de leiding tijdig t.a.v. een bepaalde ontwikkeling kan voorlichten resp. kan waarschuwen. De grotere dynamiek bracht met zich, dat ook in de vorm en de inhoud der overzichten, welke periodiek aan de leiding worden verstrekt, bij verandering van omstandigheden direct de nodige wijzigingen worden aangebracht. Opmerkelijk is de snelheid, waarmede in het algemeen de gegevens worden verstrekt.

Ter stimulering van het verantwoordelijkheidsgevoel bij de vrijere overdracht van de verantwoordelijkheden met een minder politioneel toezicht wordt dikwijls aan lager leidende organen (bijv. bazen) een behoorlijke informatie gegeven omtrent de uitvoering van de gedelegeerde taak: productie-, kosten- en rendementscijfers. Hierdoor zijn deze functionarissen "cost-minded" geworden. Dit werkt door en heeft ook een goede invloed op de arbeiders, waardoor deze laatste geinspireerd worden om verspillingen zoveel mogelijk te vermijden. De kostencijfers enz., welke aan de baas kenbaar worden gemaakt, beperken zich in het algemeen tot die, waarop hij zelf rechtstreeks invloed kan uitoefenen.

Een vereiste voor een gedetailleerd en serieus opgezet budget is het standaardiseren van de productie-omstandigheden, d.w. dus onder meer zeggen het kennen van exacte machine- en mantijden, i.c. time-study. Typisch is, dat de aan het team toegevoegde specialist op dit terrein dikwijls zijn Amerikaanse collega in de bezochte bedrijven niet heeft aangetroffen. Het is mij niet volledig bekend of de betrokken functionarissen wellicht bij het hoofdkantoor van de ondernemingen waren gedetacheerd (in een enkel geval wel) resp. of in de desbetreffende gevallen dit werk werd gedaan door zelfstandig gevestigde adviesbureaux. 
Het opzetten van het (fabrieks) budget zelve geschiedde ook niet dikwijls ter plaatse, doch in het algemeen op het hoofdkantoor. In een enkel geval werd hiertoe zelfs gebruik gemaakt van een zelfstandig gevestigd bureau van cost-accountants.

Omtrent het voorkomen van marktonderzoek op de verkoopmarkt konden weinig positieve gegevens bij de bezochte fabrieken worden verkregen. Gezien het streven naar beheersing van de omstandigheden kan verwacht worden, dat een en ander op de hoofdkantoren resp. door andere instanties voor de leiding gebeurt.

Zoals reeds gezegd acht ik persoonlijk de mentale/psychologische factoren het belangrijkste. De beste organisatie met de beste hulpmiddelen en de beste instructies kan nooit tot een succes worden, wanneer zij niet wordt gedragen door de bezieling van leiding en uitvoering. Naar mijn mening ligt in Nederland hier grotendeels een taak voor de leiding, omdat zij alle krachten zal moeten coördineren en zal moeten voorgaan in de bezieling met als doel een grotere productiviteit ten behoeve van de gehele Nederlandse samenleving. 